\title{
Giant Cell Myocarditis: Case Review
}

\author{
Meysam Khoshavi ${ }^{1}$, Ahmad Amin ${ }^{1,{ }^{*}}$, Mousa Youssef ${ }^{1}$, Sepideh Taghavi ${ }^{1}$, Nasim Naderi ${ }^{1}$, Iman \\ Divanbeigi $^{2}$, Shabnam Madadi ${ }^{1}$, Majid Haghjoo ${ }^{1}$ and Zahra Emkanjoo ${ }^{1}$ \\ ${ }^{1}$ Rajaie Cardiovascular Medical and Research Center, Iran University of Medical Sciences, Tehran, Iran \\ ${ }^{2}$ Mostofi Pathology Center, Tehran, Iran \\ "Corresponding author: Department of Heart Failure, Rajaie Cardiovascular Medical and Research Center, Iran University of Medical Sciences, Tehran, Iran. Tel: +98-2123922172, \\ Email:amina33@gmail.com
}

Received 2018 June 16; Revised 2018 August 29; Accepted 2018 September 10.

\begin{abstract}
Introduction: Although giant cell myocarditis (GCM) is a rare, potentially fatal disease but its true prevalence is likely to be underestimated. GCM can lead to progressive heart failure, fatal ventricular arrhythmia and atrio-ventricular block.

Case Presentation: The present report describes three cases of biopsy-proven GCM with clinical presentation including arrhythmia and heart failure. All patients were treated with immunosuppressant drugs.
\end{abstract}

Conclusions: Arrhythmia and symptoms of heart failure with immunosuppression had a relative improvement in three patients.

Keywords: Giant Cell Myocarditis, Arrhythmia, Immunosuppressant

\section{Introduction}

Giant cell myocarditis (GCM) is a rare, progressive and fatal myocardial disease. GCM presentation of GCM is wide spectrum such as acute coronary syndrome with nonobstructive coronary arteries, acute and subacute heart failure, ventricular arrhythmia and high grade atrioventricular block (1).

The basis of its diagnosis is endomyocardial biopsy (EMB) (2). Even with optimal medical care, GCM typically has a bad prognosis (3).

These cases have been reported for the first time in Iran.

All patients have consented to publication of information about them contained in case reports.

\section{Case Presentation}

\subsection{Case I}

A 31-year-old female presented to the medical center with palpitation followed by physical activity. She had a history of syncope one day earlier. She had no fever, history of flu-like illnesses, malaise, chills, chest pain and dyspnea. She also did not mention the past history of any extracardiac diseases, drug use and abuse, family history for sudden cardiac death (SCD) and cardiomyopathy. The first patient's electrocardiogram (ECG) showed ventricular arrhythmia with a heart rate of 150 and blood pressure 85/50 then it was converted to sinus rhythm by synchronized DC shock (Figure 1A). ECG of sinus rhythm revealed ST-T change in anterolateral leads (Figure 1B). The general physical exam was normal cardiovascular examination after arrhythmia conversion had S4 and mid systolic murmur grade II/VI. Lab data showed ESR: $34 \mathrm{~mm} / \mathrm{h}$, anti-CCP (cyclic citrullinated peptide): $9 \mathrm{U} / \mathrm{mL}$, troponin :0.53 ng/mL, other lab data, chest x-ray and abdominal sonography was normal. Echocardiography revealed moderate to severe global left ventricular (LV) dysfunction with estimated ejection fraction (EF): 30\% - 35\%, mild mitral regurgitation (MR), severe apical and posterior hypokinesia and mild pericardial effusion (PE).

Ventricular arrhythmia frequently happened, so coronary angiography was done and the results were normal. Cardiac magnetic resonance (CMR) imaging showed acute extensive myocarditis with left ventricular involvement of anterolateral, inferolateral and apical segment (Figure $1 C$ ).

Therefore, EMB was done and showed mild infiltration of lymphocytes, macrophage and multinucleated giant cell (Figure 1D). With due attention to frequent ventricular arrhythmia, the patient underwent VT ablation and insertion of implantable cardioverter defibrillator (ICD).

Despite the treatment of arrhythmia, it continued and as a result the patient was treated initially by methyl prednisolone infusion (500 $\mathrm{mg}$ ) a day in three doses then continuing with $15 \mathrm{mg}$ oral prednisolone and mycophenolate mofetil (MMF) (1 g daily) in addition to metoprolol succinate, spironolactone, lisinopril and amiodarone. Arrhythmia and hospitalization decreased after 12 months of therapy. 

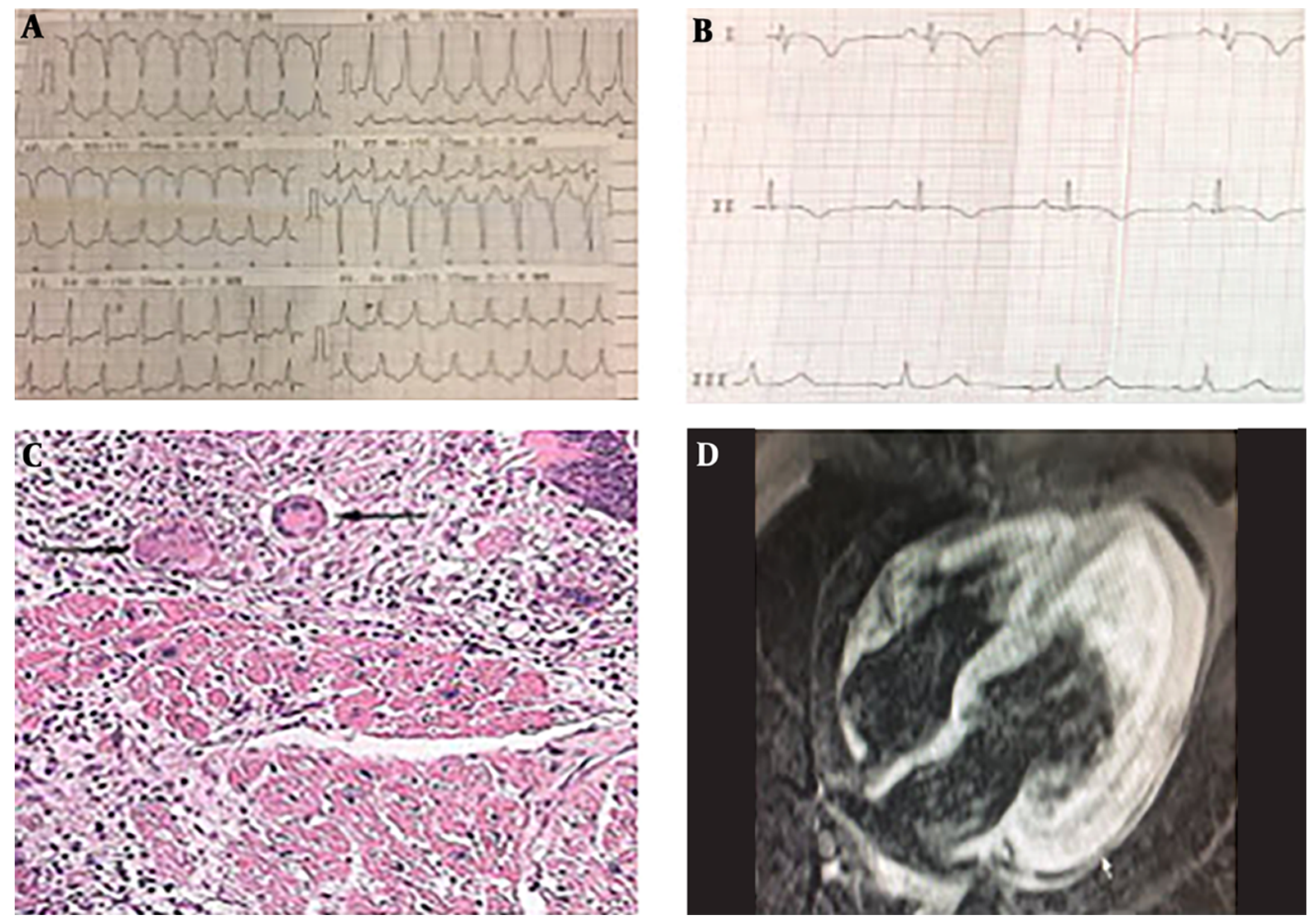

Figure 1. A, Ventricular tachycardia probably with mitral ring origin; B, sinus rhythm with ST-T change; C, histopathological view of myocardial sample revealed giant cell and inflammation; D, cardiac MR with diffuse myocardial edema in the short inversion time inversion recovery (STIR) technique

\subsection{Case II}

A 45-year-old woman admitted with syncope, chest pain and dyspnea to Rajaie Heart Center. She was in respiratory distress and complete atrio-ventricular block. Heart rate was 45 beat/min and blood pressure was $85 / 50 \mathrm{mmHg}$. She was afebrile but she had diaphoresis, cold sweating and weak arterial pulse.

ECG revealed complete heart block $(\mathrm{CHB})$ and intraventricular conduction delay (IVCD) (Figure 2B). Lab data showed troponin: $1.8 \mathrm{ng} / \mathrm{dL}$, NT-proBNP: $18000 \mathrm{pg} / \mathrm{mL}$ and normal electrolyte range.

Echocardiography revealed severe biventricular dysfunction, LVEF: 10\% - 15\% moderate MR, mild PE. Temporary pacemaker (TPM) was placed for 72 hours then dualchamber ICD was implanted. Furosemide, milrinone and norepinephrine infusion were initially started. Then some episodes of sustain VT happened (Figure 2B). Regarding the patent coronary arteries in angiography, she underwent EMB from right ventricle (RV). EMB showed diffuse infiltration of myocardium by many lymphocyte, macrophage, eosinophil and scattered multinucleated giant cells (Figure $2 \mathrm{~A})$.

Therefore, methylprednisolone was started $1 \mathrm{~g}$ per day for 3 days then oral prednisolone (15 mg daily) with MMF (1 g daily) continued.

The patient's LV and RV function partially improved in a few days and CHB have been resolved. The cardiogenic shock was over but patient's struck thrombocytopenia and sepsis was diagnosed disseminated intravascular coagulation (DIC) and despite broad spectrum antibiotic and platelet infusion, the patient expired with hemothorax and sepsis.

\subsection{Case III}

A55-year-old woman referred with frequent syncope to emergency department in evaluation. Diagnosis of sustain VT was confirmed. She had no symptoms of flu-like illness and chest pain.

Lab data was fine. She did not notice symptoms of heart failure. 

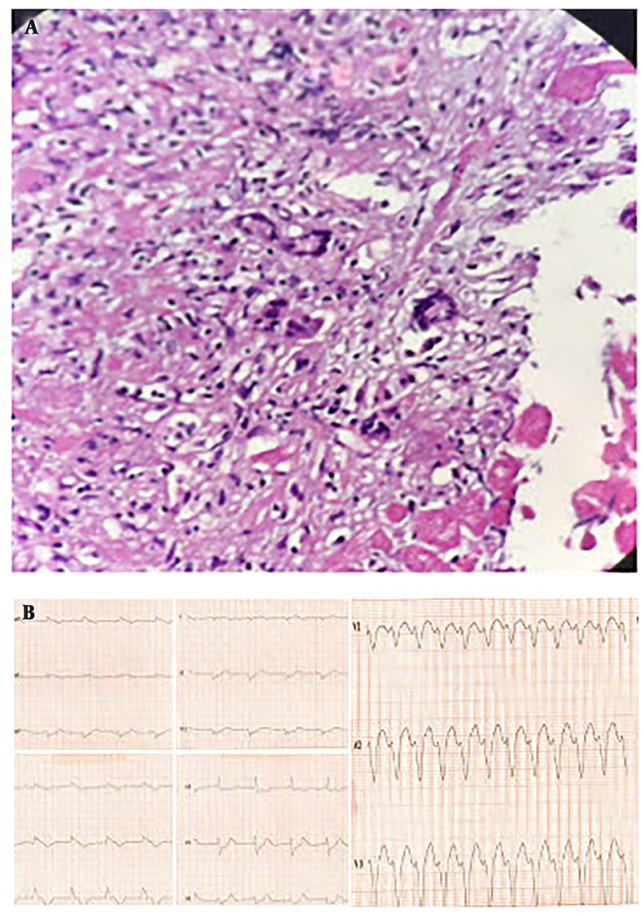

Figure 2. A, Histopathologic view of myocardial sample showed multiple giant cells, severe inflammation and necrosis; B, A-V block and VT respectively.

ECG showed nonspecific ST-T change (Figure 3A). Echocardiography showed LVEF: 45\%, no significant valvular disease, normal LV and RV size.

Therefore, she underwent coronary angiography which was patent. CMR has revealed myocarditis (Figure 3B) based on Lake Louise criteria (4).

Antiarrhythmic drug (mexiletine and amiodarone) and bisoprolol was started for patient then ICD was implanted.

But frequent ICD shock has happened due to sustain monomorphic VT, so she was referred for VT ablation. Considering the recent positive troponin, cardiomyopathy and frequent VT with medical therapy, EMB was done during the procedure of VT ablation.

EMB revealed multiple giant cells, asteroid body, lymphocyte and macrophage infiltration (Figure 3C and 3D). Viral polymerase chain reaction (PCR) test was performed for myocardial sample detected parvovirus B19. Computed tomography chest scan showed a normal pattern. Thus, she was treated with $1 \mathrm{mg} / \mathrm{kg}$ oral prednisolone and cyclosporine 100 twice daily and MMF (1 g daily). Prednisolone was tapered to $15 \mathrm{mg}$ daily and serum cyclosporine level has been maintained at $80-100 \mathrm{ng} / \mathrm{mL}$.

At this point no VT and ICD shock has been repeated so far. LV function was estimated $55 \%$. The patient was underwent left ventricular biopsy that revealed inflamma- tion cores less than the previous sample after 1year (Figure 4). Second EMB did not indicate asteroid body and giant cell. So, cyclosporine was discontinued.

\section{Discussion}

GCM is an underdiagnosed inflammatory myocardial disease all over the world. It has often been diagnosed after death or heart transplantation $(5,6)$.

Although GCM is known as a rare myocardial disease but its incidence has been reported $0.2 \%$ to $5 \%$ in EMB based myocarditis $(7,8)$.

GCM is commonly happening at young and middleaged adults $(1,9)$.

In our series, the mean age of patients is 44.3 years that all of whom are women. These characteristics are consistent with previous studies $(3,6,10)$.

The main clinical presentation of GCM is progressive heart failure (64\% - 75\%). Other clinical manifestations are high grade A-V block (5\% - 31\%), ventricular arrhythmia (VTVF) (14\% - 32\%), acute coronary like syndromes (6\% - 19\%) (1, $6,9,11)$.

Approximately $20 \%$ of GCM cases have autoimmune disorders such as collagen vascular disease, thyroiditis or inflammatory bowel disease (12).

In our cases, the common symptoms were VT (occurring in three patients), $\mathrm{CHB}$ (the second case), heart failure (the second case).

Clinical diagnosis of GCM especially for middle aged woman should be suspected in the approach to a patient with ventricular arrhythmia and high grade A-V block even without significant LV dysfunction. Importance of GCM differential diagnosis especially with AVB is cardiac sarcoidosis $(13,14)$.

There are limited data on the use of non-invasive imaging such as cardiac MR and nuclear imaging (15). CMR was done in two of our cases which other than myocardial edema, in the first case, CMR showed a thick layer of myocardial late gadolinium enhancement (LGE) that was extended from sub epicardial to intramural LV. The third patient had LGE (sub endocardium) in inferolateral LV.

A recent report, compared CMR with histology in GCM, in which strain-encoded CMR showed a patchy distribution of LGE affecting all layers of myocardium (15).

Table 1 illustrates diagnostic importance of common imaging modalities in specific myocarditis (15).

Although non-invasive imaging cannot provide a definite distinction between inflammatory cardiomyopathy, but those are (especially CMR) standard references for initial and complementary assessment of myocardial tissue characterization and function (16).

EMB and histologic examination is the gold standard method for the diagnosis of GCM (17). The giant cells are the main characteristic feature of GCM (12). The classic 

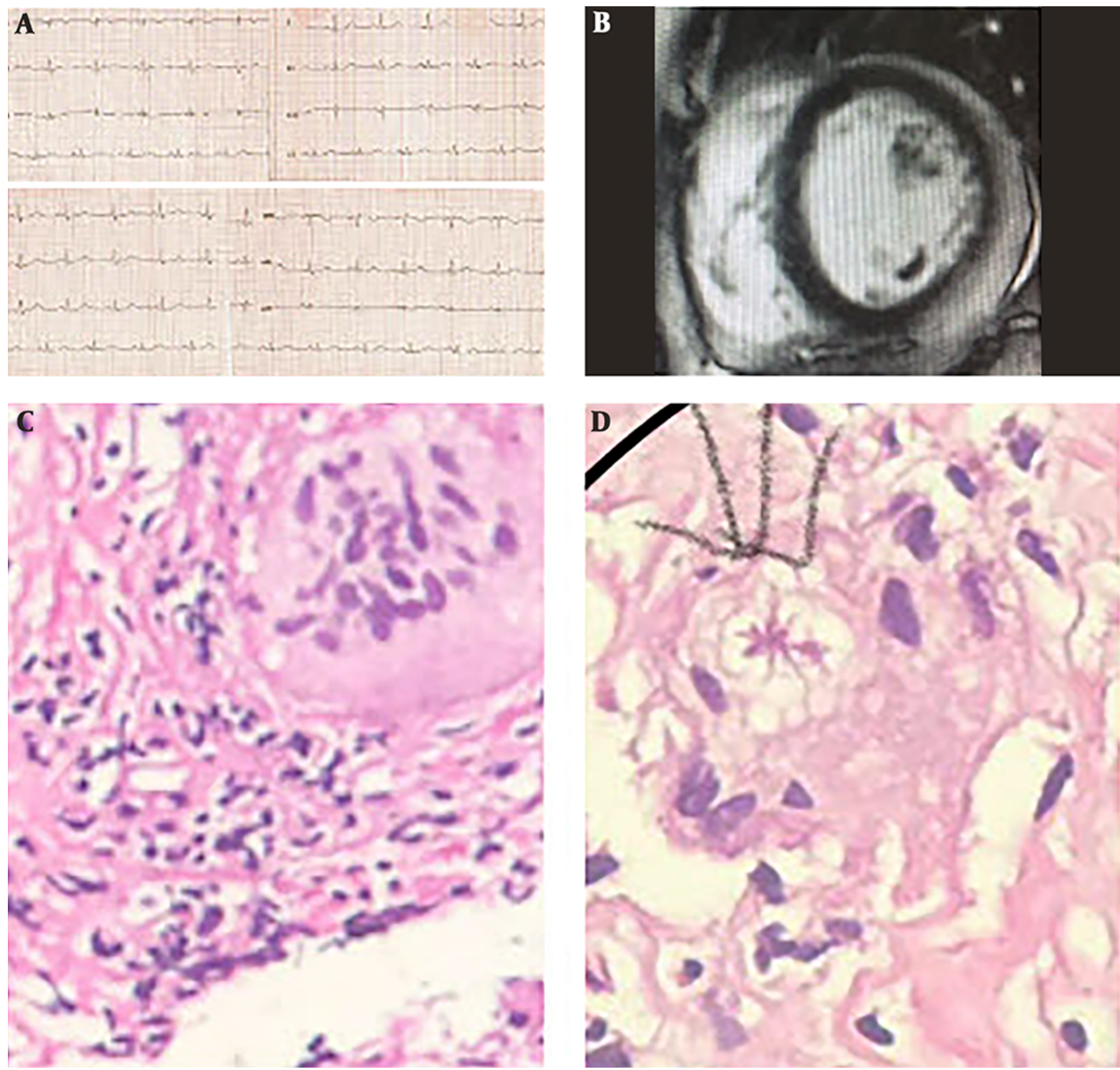

Figure 3. A, Electrocardiogram with sinus rhythm; B, myocardial edema in CMR; C, giant cell and inflammation in pathology; D, asteroid body

Table 1. Kadkhodayan et al. (15)

\begin{tabular}{lccc}
\hline Imaging Modality & CMR & Echocardiography & Nuclear Imaging (18F-FDG PET) \\
\hline Cardiac sarcoidosis & + & ++ & +++ \\
Giant cell myocarditis & + & + & + \\
Eosinophilic myocarditis & ++ & ++ & + \\
Lymphocytic myocarditis & + & + & + \\
\hline
\end{tabular}

histopathologic view of GCM are diffused myocyte necrosis with inflammatory cell infiltration including eosinophils, lymphocytes, multinucleated giant cells, plasma cells and neutrophils $(9,12,18,19)$.

The major differential diagnosis of GCM in histopathology are other myocardial lesion containing giant cells including sarcoidosis, infectious granulomatosis myocardi- tis, giant cell arteritis and Takayasu's arteritis $(4,20)$.

Myocardial histopathology of the third case revealed giant cells with asteroid body but her imaging and clinical feature did not suggest cardiac sarcoidosis (CS). The pathologic characteristic features of CS to differentiate from GCM include non-necrotizing granuloma with giant cell and intracytoplasmic inclusions such as Schaumann and 

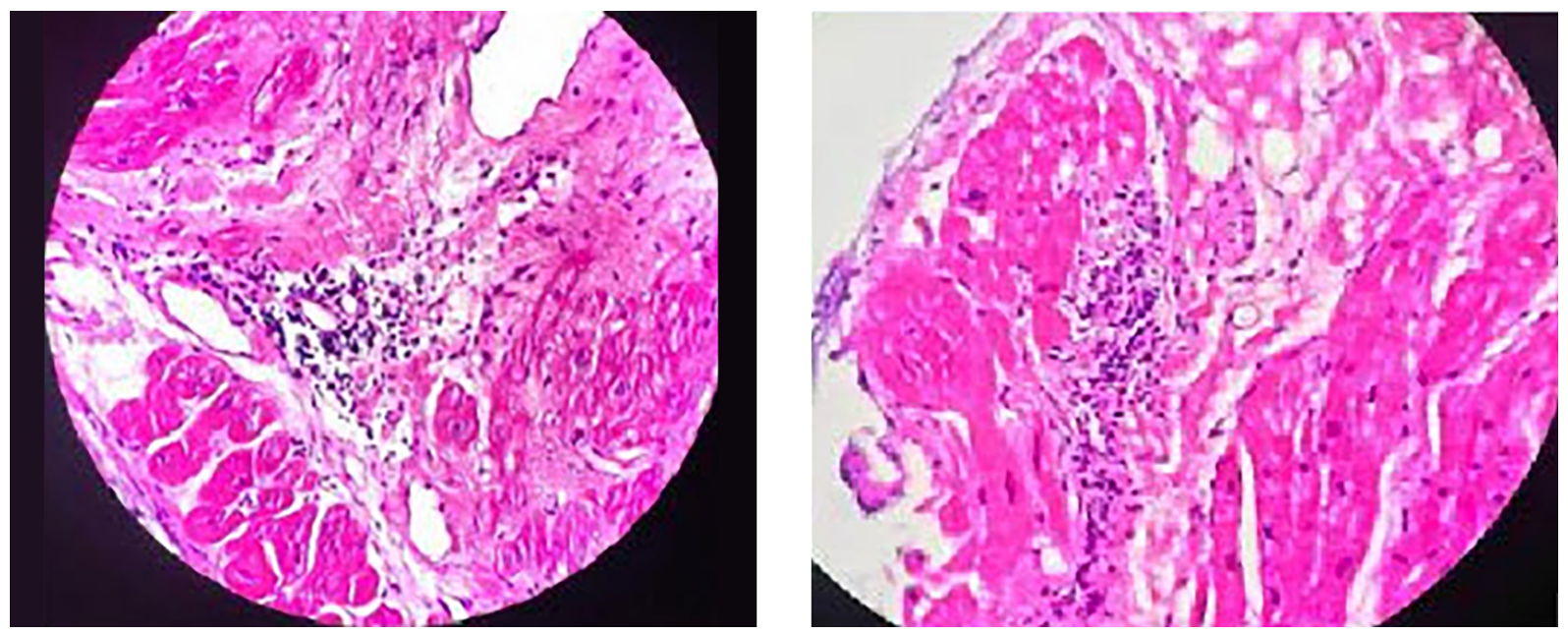

Figure 4. Histopathologic view of LV sample revealed lymphocytic infiltration without giant cells

asteroid bodies (21).

However, the third case has been following for CS presentation. Our second case showed massive myocardial necrosis and severe inflammatory cells infiltration. With due attention to her very poor prognosis, it is possible to consider the relationship between myocardial pathologic view and clinical prognosis.

The simultaneous presence of parvovirus B19 genome and GCM can show triggering effect of parvovirus B19 infection on giant cell myocarditis (22).

There are no sufficient data management and follow up GCM (23). Kandolin et al. reported that 26 biopsy GCM diagnosed patients were treated with combined immunosuppression that included steroid (all patients), cyclosporine, mycophenolate mofetil, muromonab, gamma globulin and methotrexate. This report described that two third of patients partially recovered from severe clinical heart failure but continued the susceptibility to ventricular arrhythmia (6).

Five patients (total mortality) died due to ventricular arrhythmia. Twenty-five patients received beta-blocker (6).

Several other reports described the efficacy of immunosuppression therapy such as steroid, muromonab, cyclosporin, anti-thymocyte globulin (ATG) and mycophenolate mofetil that can be effective in relative clinical remission of $\operatorname{GCM}(9,11,24,25)$.

Our first case was treated with steroid and MMF that achieved partial remission for ventricular arrhythmia.

In the second case, RV and LV functions were relatively recovered with steroid pulse and MMF.

The third patient was improved in the view of myocardial function and ventricular arrhythmia. Of course, arrhythmia ablation has been performed for her. However, it is clear that immunosuppressant drugs can partially control clinical heart failure and arrhythmia (7).

Further research specially clinical trials are required for drug combinations.

Anti heart-failure drugs (angiotensin-converting enzyme or angiotensin receptor blockers and B-blockers) have been used for our patients according to guidelines (26).

Specific guideline does not exist for re-biopsy in GCM to diagnose and follow up of the treatment and to estimate prognosis (2) but considering the results of the third-case re-biopsy, it is advisable to further research for re-biopsy and left ventricular biopsy in patients with GCM.

\subsection{Conclusion}

It is important to consider especially giant cell myocarditis in tachyarrhythmia and bradyarrhythmia with unknown origin, in particular for young and middle aged patients. Altogether, immunosuppressants can help to manage GCM, but clinical trials are necessary.

\section{References}

1. Okura Y, Dec GW, Hare JM, Kodama M, Berry GJ, Tazelaar HD, et al. A clinical and histopathologic comparison of cardiac sarcoidosis and idiopathic giant cell myocarditis. J Am Coll Cardiol. 2003;41(2):322-9. [PubMed: 12535829].

2. Kalra A, Kneeland R, Samara MA, Cooper LT Jr. The changing role for endomyocardial biopsy in the diagnosis of giant-cell myocarditis. Cardiol Ther.2014;3(1-2):53-9. doi:10.1007/s40119-014-0028-5. [PubMed: 25135591]. [PubMed Central: PMC4265228].

3. Kandolin R, Lehtonen J, Kupari M. Cardiac sarcoidosis and giant cell myocarditis as causes of atrioventricular block in young and middle-aged adults. Circ Arrhythm Electrophysiol. 2011;4(3):303-9. doi: 10.1161/CIRCEP.110.959254. [PubMed: 21427276]. 
4. Friedrich MG, Sechtem U, Schulz-Menger J, Holmvang G, Alakija P, Cooper LT, et al. Cardiovascular magnetic resonance in myocarditis: A JACC White Paper. J Am Coll Cardiol. 2009;53(17):1475-87. doi: 10.1016/j.jacc.2009.02.007. [PubMed: 19389557]. [PubMed Central: PMC2743893].

5. Okada R, Wakafuji S. Myocarditis in autopsy. Heart Vessels Suppl. 1985;1:23-9. [PubMed: 2956238].

6. Kandolin R, Lehtonen J, Salmenkivi K, Raisanen-Sokolowski A, Lommi J, Kupari M. Diagnosis, treatment, and outcome of giant-cell myocarditis in the era of combined immunosuppression. Circ Heart Fail. 2013;6(1):15-22. doi: 10.1161/CIRCHEARTFAILURE.112.969261. [PubMed: 23149495].

7. Davidoff R, Palacios I, Southern J, Fallon JT, Newell J, Dec GW. Giant cell versus lymphocytic myocarditis. A comparison of their clinical features and long-term outcomes. Circulation. 1991;83(3):953-61. [PubMed: 1999043].

8. Davies RA, Veinot JP, Smith S, Struthers C, Hendry P, Masters R. Giant cell myocarditis: Clinical presentation, bridge to transplantation with mechanical circulatory support, and long-term outcome. J Heart Lung Transplant. 2002;21(6):674-9. [PubMed: 12057701].

9. Cooper LT Jr, Berry GJ, Shabetai R. Idiopathic giant-cell myocarditisnatural history and treatment. Multicenter giant cell myocarditis study group investigators. N Engl J Med. 1997;336(26):1860-6. doi: 10.1056/NEJM199706263362603. [PubMed: 9197214].

10. Caforio AL. Long term risk of recurrence, morbidity and mortality in giant cell myocarditis. Am J Cardiol. 2015.

11. Cooper LT Jr, Hare JM, Tazelaar HD, Edwards WD, Starling RC, Deng MC et al. Usefulness of immunosuppression for giant cell myocarditis. Am J Cardiol. 2008;102(11):1535-9. doi: 10.1016/j.amjcard.2008.07.041. [PubMed: 19026310]. [PubMed Central: PMC2613862].

12. Cooper LT Jr. Giant cell myocarditis: Diagnosis and treatment. Herz. 2000;25(3):291-8. [PubMed: 10904855].

13. Yoshida Y, Morimoto S, Hiramitsu S, Tsuboi N, Hirayama H, Itoh T. Incidence of cardiac sarcoidosis in Japanese patients with highdegree atrioventricular block. Am Heart J.1997;134(3):382-6. [PubMed: 9327691].

14. Banba K, Kusano KF, Nakamura K, Morita H, Ogawa A, Ohtsuka F, et al. Relationship between arrhythmogenesis and disease activity in cardiac sarcoidosis. Heart Rhythm. 2007;4(10):1292-9. doi: 10.1016/j.hrthm.2007.06.006. [PubMed: 17905334].

15. Kadkhodayan A, Chareonthaitawee P, Raman SV, Cooper LT. Imaging of inflammation in unexplained cardiomyopathy. Cardiovas Imag. 2016;9(5):603-17. doi: 10.1016/j.jcmg.2016.01.010.
16. Adam RD, Shambrook J, Flett AS. The prognostic role of tissue characterisation using cardiovascular magnetic resonance in heart failure. Card Fail Rev. 2017;3(2):86-96. doi: 10.15420/cfr.2017:19:1. [PubMed: 29387459]. [PubMed Central: PMC5739890].

17. Xu J, Brooks EG. Giant cell myocarditis: A brief review. Arch Pathol Lab Med. 2016;140(12):1429-34. doi: 10.5858/arpa.2016-0068-RS. [PubMed: 27922771].

18. Vaideeswar P, Cooper LT. Giant cell myocarditis: Clinical and pathological features in an Indian population. Cardiovasc Pathol. 2013;22(1):70-4. doi: 10.1016/j.carpath.2012.06.003. [PubMed 22863545].

19. Steger CM, Hofer D, Antretter H. Giant cell and granulomatous myocarditis necessitating cardiac transplantation: Clinical, gross, and histopathological findings. Euro Surg. 2014;46(5):209-15. doi 10.1007/s10353-014-0269-5.

20. Rosenstein ED, Zucker MJ, Kramer N. Giant cell myocarditis: Most fatal of autoimmune diseases. Semin Arthritis Rheum. 2000;30(1):1-16. doi: 10.1053/sarh.2000.8367. [PubMed: 10966208].

21. Lagana SM, Parwani AV, Nichols LC. Cardiac sarcoidosis: A pathologyfocused review. Arch Pathol Lab Med. 2010;134(7):1039-46. doi: 10.1043/2009-0274-RA.1. [PubMed: 20586635].

22. Dennert R, Schalla S, Suylen RJ, Eurlings L, Heymans S. Giant cell myocarditis triggered by a parvovirus B19 infection. Int J Cardiol. 2009;134(1):115-6. doi: 10.1016/j.ijcard.2007.12.020. [PubMed: 18280593].

23. Menghini VV, Savcenko V, Olson LJ, Tazelaar HD, Dec GW, Kao A, et al. Combined immunosuppression for the treatment of idiopathic giant cell myocarditis. Mayo Clin Proc. 1999;74(12):1221-6. [PubMed: 10593350].

24. Grabmaier U, Brenner C, Methe H, Kaczmarek I, Schramm R, Klingel $\mathrm{K}$, et al. An alternative immunosuppressive regimen to prolong transplant free survival in a patient with giant cell myocarditis. Int J Cardiol. 2013;168(1):e27-8. doi: 10.1016/j.ijcard.2013.05.078. [PubMed: 23735345].

25. Frustaci A, Chimenti C, Pieroni M, Gentiloni N. Giant cell myocarditis responding to immunosuppressive therapy. Chest. 2000;117(3):905-7. [PubMed: 10713027].

26. Yancy CW, Jessup M, Bozkurt B, Butler J, Casey DE Jr, Drazner MH, et al. 2013 ACCF/AHA guideline for the management of heart failure: A report of the American College of Cardiology Foundation/American Heart Association Task Force on Practice Guidelines. J Am Coll Cardiol. 2013;62(16):e147-239. doi: 10.1016/j.jacc.2013.05.019. [PubMed 23747642]. 